\title{
POLÍTICAS DE AVALIAÇÃO DA EDUCAÇÃO E QUASE MERCADO NO BRASIL
}

\author{
Sandra Zákia Lian de Souza* \\ Romualdo Portela de Oliveira*
}

RE SU M 0 : Como um dos elementos estruturantes da transformação do papel do Estado na oferta e gestão da educação, tem-se a discussão e implantação da noção de quase-mercado, desde as décadas de 1980 e 1990, especialmente nos Estados Unidos e Inglaterra, cujas iniciativas têm sido referência para diversos países. Utilizando a noção de quase-mercado, neste texto apresenta-se como expressão de um continuum de formas organizacionais que vão do mercado puro à gestão e financiamento estatal da educação, apresenta-se uma análise de características que têm estado presentes, de modo dominante, na concepção e condução de avaliações dos sistemas e instituições de ensino no Brasil. Procura-se evidenciar que a adoção de uma lógica competitiva como promotora de qualidade, articulada à implantação de incentivos, tende a produzir resultados socialmente injustos.

Palavras-chave: Quase-mercado. Avaliação. Política educacional.

\section{EDUCATIONAL ASSESSMENT POLICIES AND QUASI-MARKET IN BRAZIL}

A BSTRA CT: Since the 80s and 90s, the discussion of the notion of quasi-market and its implementation have constituted one of the structuring elements of the transformation of the State's role in the supply and administration of education, especially in the United States and England. Such initiatives have constituted a reference for other countries. Based on the notion of quasi-market, which expresses a continuum of organizational forms ranging from a perfect market to the state administration and financing of education, this text presents an analysis of the features that have been dominantly present in the conception and conduction of system and institutional assessment of education in Brazil. It aims at underlining that

\footnotetext{
* D outora em Educação e professora da Faculdade de Educação da usp. E -mail: sanzakia@ usp.br

* Doutor em Educação e professor da Faculdade de Educação da usP. E-mail: romualdo@ usp.br
} 
adopting a competitive logic to promote quality, together with the implantation of incentives, tends to produce socially unjust outcomes.

Key words: Quasi-market. Assessment. Educational policy.

\section{Introdução: o novo papel da educação e as políticas de avaliação}

$7 \begin{aligned} & \text { dimensão da globalização da economia desencadeada pela Revo- } \\ & \text { lução Informacional (Lojkine, 1995), além de significativas mu- } \\ & \text { danças na ordem social, econômica e política contemporânea, al- }\end{aligned}$ tera o tipo de demanda por educação. D o trabalhador desqualificado da linha taylorista passa-se a demandar um trabalhador capaz de tomar decisões, de adaptar-se a constantes mudanças e de aperfeiçoar-se pela vida toda (D elors, 1999).

A educação, chamada a formar o trabalhador flexível que o novo processo produtivo demanda, adquire importância de natureza distinta na qualificação da força de trabalho, superando a função ideológica que lhe era atribuída sob as tecnologias da Segunda Revolução Industrial (Salm, 1980).

Ao mesmo tempo em que o capital e a lógica de mercado penetram em áreas em que até então sua presença era limitada, a educação passa a constituir um mercado em acentuada expansão, em escala mundial. Isso tem ensejado uma modificação nos objetivos gerais das políticas educacionais, tanto nos países centrais como nos países em desenvolvimento, em particular, no Brasil. Inclui-se todo o processo educacional na esfera do mercado e generalizam-se os procedimentos e valores típicos do capitalismo competitivo na gestão dos sistemas e das instituições educacionais. O debate em curso acerca do Acordo Internacional de Tarifas e Comércio no âmbito da Organização Mundial do Comércio (GATT-OMC) é uma expressão do primeiro aspecto, a generalização dos sistemas de avaliação em larga escala, do segundo.

O objetivo deste artigo é analisar a centralidade adquirida pela avaliação educacional na configuração dos sistemas de ensino nestas duas últimas décadas, ressaltando que esta tem sido apresentada e justificada como propulsora de sua "qualidade", substituindo a antiga "idéia força" da "igualdade" como principal objetivo das políticas educacionais (Gentili \& Silva, 1995). Essa contraposição entre qualidade e igualdade torna-se mais clara quando compreendida dentro dos marcos gerais das reformas educacionais recentes. De um lado, centralizam-se os processos avaliativos e, de outro, descentralizam-se os mecanismos de gestão e financiamento, tornando-os meios destinados a "otimizar" o produto es- 
perado, os bons resultados no processo avaliativo. A avaliação torna-se então um mecanismo indutor da excelência e, como desdobramento, naturaliza-se a desigualdade (O rfield \& Kornhaber, 2001; O liveira, 2000).

D entro dessa lógica, a avaliação encerra duas potencialidades bastante funcionais. De um lado, torna-se peça central nos mecanismos de controle, que se deslocam dos processos para os produtos, transferindose 0 mecanismo de controle das estruturas intermediárias para a ponta, via testagens sistêmicas, "os controles remotos" (Lima, 2000, p. 65). Não importa como ocorre o processo ensino-apredizagem, desde que ocorra. 0 controle por meio de pesadas estruturas organizacionais, que ademais demandam corpos de funcionários especializados (os "supervisores") torna-se desnecessário, sendo substituído por processos avaliativos que verificam o produto da ação da escola, certificando sua "qualidade".

D e outro, a avaliação legitima "valorações" úteis à indução de procedimentos competitivos entre escolas e sistemas para melhorar pontuações nos rankings, definidos basicamente pelos desempenhos em instrumentos de avaliação em larga escala. Tal competição é garantida pela associação entre desempenho e financiamento, podendo redundar em critérios para alocação de recursos, que incidem, até mesmo, em remunerações diferenciadas dentro de sistemas de ensino que até a pouco trabalhavam com a noção de remunerações isonômicas.

Tais modificações, apesar de alicerçarem-se na lógica de mercado, não se enquadram no modelo típico da sociedade capitalista, de privatização e competição entre agentes econômicos "livres" e autônomos. Pela especificidade da oferta de serviços sociais, necessitar-se-ia conceber algo intermediário entre as estruturas estatais, alheias à lógica de mercado, e o mercado concorrencial típico. Ressalte-se que a proposição educacional característica da razão neoliberal é 0 voucher, conhecido, entre nós, como ticket-educação ou vale-educação (Friedman, 1985; Chubb \& Moe, 1990).

Dada a impossibilidade da abordagem típica, buscou-se a formulação de um quadro aproximativo, em que alguns valores de mercado possam ser utilizados. Para responder a essa especificidade da educação, recorre-se à noção de "quase-mercado".

\section{O "quase-mercado" educacional}

A companhada das modificações no plano infra-estrutural, com as alterações no processo produtivo, a hegemonia do pensamento neoliberal nas últimas duas décadas buscou, também, generalizar a 
sua visão de mundo para todas as esferas da atividade humana. A conhecida crítica à "ineficiência" do Estado gerou diferentes formas de privatização. Uma, que pode ser chamada de stricto sensu, tratou de transferir a propriedade de setores estatais para a iniciativa privada, numa perspectiva de enxugamento da ação econômica do Estado. A outra, mais matizada, tratou de disseminar formas de gestão ancoradas na lógica de mercado. Nesse caso, não se discute a propriedade da empresa, mas se introduzem concepções privadas de gestão. Esta alternativa, quer seja pela natureza do procedimento, quer seja pela natureza da área não comportava uma transferência direta para 0 mercado, pelo menos em sua acepção mais "perfeita". ${ }^{1}$ Um dos fundamentos das propostas de privatização stricto sensu era submeter as organizações a um "choque de mercado", por meio dos efeitos salutares da concorrência. Na oferta de serviços educacionais, a adoção de mecanismos típicos de mercado é bastante limitada. Seja por razões geográficas, em uma mesma região não é grande o número de "escolhas" disponíveis, seja por limitações à concorrência devido às regulações governamentais (Whitty, 1998, p. 193). A concorrência não se estabelece, portanto, de maneira "perfeita". Segundo Fernando Abrucio,

O pressuposto do modelo da competição é de que os consumidores podem escolher a unidade de serviço público de maior qualidade. Contudo, esse pressuposto nem sempre é verdadeiro, pois nem todos os consumidores têm a possibilidade de escolher de fato o equipamento social que lhes agrada, em virtude da existência de obstáculos geográficos e financeiros, os quais dificultam 0 acesso a todas as unidades de serviço público. Ademais, se todos os consumidores (ou boa parte deles) escolherem um número limitado de equipamentos sociais, estes ficarão lotados e tenderão também a perder qualidade. (Abrucio, 1999, p. 189)

Buscou-se então uma alternativa de gestão que superasse a dicotomia, gestão "estatal-centralizada-burocrática-ineficiente" de um lado, "mercado-concorrencial-perfeito" de outro. A alternativa encontrada foi a de introduzir concepções de gestão privada nas instituições públicas sem alterar a propriedade das mesmas.

Assim, o debate sobre charter schools nos Estados Unidos é feito concebendo essa alternativa como uma formulação diferente da dos vouchers, estes sim típicos da esfera do mercado. As charters seriam organizações destinadas a melhorar o controle social sobre a oferta dos serviços escolares por parte dos usuários, criando um controle externo indutor de melhorias sem, no entanto, privatizá-los, ao mesmo tempo em que propiciam mais participação da comunidade na confor- 
mação de seu perfil, pois a ameaça da "saída" dos alunos funcionaria como importante indutor de aperfeiçoamento.

Surge, assim, a noção de "quase-mercado" que, tanto do ponto de vista operativo, quanto conceitual, diferencia-se da alternativa de mercado propriamente dita, podendo, portanto, ser implantada no setor público sob a suposição de induzir melhorias.

As medidas cabíveis dentro dessa lógica podem ser diversas, mas, no caso da educação, os mecanismos que têm evidenciado maior potencial de se adequarem a ela são as políticas de avaliação, associadas ou não a estímulos financeiros. Ao se buscar um dos marcos importantes para essa emergência das políticas de avaliação, geralmente são mencionados o relatório Coleman, de 1966, e "A nation at risk", de 1983.

\section{Um pouco de história: "A nation at risk"}

Como referência mais recente desse processo, "A nation at risk" é a influência mais significativa. Em abril de 1983, a Comissão Nacional para a Excelência na Educação publicou o seu "report", produto de 21 meses de trabalho. Este "report" desencadearia a onda reformista na educação americana nos anos 80 e 90. Bombasticamente denominado "A nation at risk: the imperative for educational reform" (1983).

Em sua estrutura o documento é bastante simples. Em 36 páginas apresenta um breve diagnóstico, os mecanismos disponíveis para reverter os problemas localizados e esboça cinco grupos de recomendações, propondo:

1. Cinco conteúdos básicos para a escola média (inglês, matemática, ciências, estudos sociais e ciências da computação);

2. A adoção de "padrões mais vigorosos e mensuráveis";

3. Mais tempo para o aprendizado dos conteúdos básicos;

4. Aperfeiçoar a preparação de professores e tornar a profissão mais compensatória e respeitável na sociedade;

5. Valorizar a liderança educacional responsável por implantar essas recomendações e dotá-la de suporte financeiro.

A primeira questão que nos parece pertinente é: Por que este e não um dos outros inúmeros "reports" sobre educação tornou-se um marco nos debates nos eUA e no exterior nos anos 80, chegando mes- 
mo a, dez e vinte anos depois, receber avaliações (Lund \& Wild, 1993; Petersen, 2003), quando o destino usual de tais documentos é o esquecimento?

Uma primeira demonstração deste impacto é o editorial do The N ew York Times de 09/ 06/ 83, que afirma: "[O "report"] trouxe a questão da educação para a ordem do dia do debate político com uma urgência não sentida desde que o satélite soviético chocou a confiança norte americana nas suas escolas públicas em 1957" (citado em Goldberg \& Renton, 1995, p. 19).

Em geral, tal tipo de repercussão se dá quando a proposta consegue captar as angústias e a consciência de seu tempo. Nesse sentido é interessante observar-se que a comissão foi convocada por Terrel Bell, Secretário de Educação do Governo Ronald Reagan. ${ }^{2}$ A avaliação de Milton Goldberg, um dos membros da Comissão responsável pelo "report", é interessante para elucidar a relação com o governo:

Políticos de ambos os lados do espectro tinham suas dúvidas a respeito do "report". Muitos na administração Reagan tomaram-no como sendo uma rejeição da plataforma educacional do presidente, pois nenhum dos pontoschave da proposta Reagan - vouchers, pregador religioso na escola e a eliminação do D epartamento de Educação - foi mencionado. Ao contrário, 'A nation at risk' delineou um número importante de responsabilidades para 0 governo federal. O ponentes da administração, por seu turno, interpretaram o "report" como um endosso das críticas de Reagan ao "establishment", esquecendo-se que 'A nation at risk' havia sido criada pelo Secretário de Educação, Terrel Bell, e representava a visão independente da Comissão pela Excelência. (Goldberg \& Renton, 1995, p. 20)

A ulterior repercussão do texto parece confirmar esta avaliação. Mesmo que se possa atribuir ao "report" uma concepção conservadora de educação, mais do que se alinhar ao discurso governamental, este sim conservadoramente tradicional, "A nation at risk" terá um papel fundante na atualização do discurso conservador em educação, transcendendo os interesses imediatos da administração Reagan. Goldberg \& Rentom observam com precisão que

apesar de significativos esforços de melhoria da educação tenham antecedido sua divulgação, o "report" serviu como um poderoso catalisador, trazendo as pessoas para a ação, e desencadeando um movimento pela reforma educacional sem precedentes na história norte-americana. (Idem, ibid.)

Como conseqüência, generalizaram-se as avaliações sistêmicas como critério de validação da qualquer iniciativa educacional. Se os 
"padrões", aferidos por meio de testes, aumentam, a iniciativa é válida, caso contrário, não. São escassas as vozes, ainda hoje, dissonantes. D estaque-se, entre estas, o trabalho de David Berliner e Bruce Biddle (1995), que procura evidenciar a um tempo que a premissa dos reformadores está errada, os "padrões" não estão caindo e, portanto, 0 diagnóstico de que a nação está "em risco" é equivocado e propositalmente alarmista, de forma a difundir uma perspectiva de reforma que rompa com os padrões vigentes de financiamento público da educação e das práticas correntes.

A avaliação a serviço da noção de quase-mercado: mérito e hierarquia

Pautados na idéia de quase-mercados, analisaremos como, no Brasil, as iniciativas de avaliação desencadeadas pelo poder executivo federal a partir dos anos $90,{ }^{3}$ reproduzidas com adaptações por diversos sistemas estaduais e municipais de educação, têm servido para viabilizar uma lógica de gerenciamento da educação, reconfigurando, por um lado, o papel do Estado e, por outro, a própria noção de educação pública, ao difundir uma idéia de qualidade que supõe diferenciações no interior dos sistemas públicos de ensino, como condição mesma de produção de qualidade.

Estudos que visem identificar os impactos já produzidos pelas avaliações nos sistemas e instituições de ensino, no Brasil, são ainda escassos, portanto fazem-se necessárias investigações que busquem apreciar como vem sendo assimilada, por "gestores" e "clientes" dos sistemas educacionais, a lógica do mercado. Por esta razão, as considerações aqui tratadas têm como foco o delineamento assumido pelas propostas governamentais de avaliação e a divulgação de seus resultados.

Trata-se de explicitar como as iniciativas em curso têm se pautado na perspectiva da privatização do ensino, via mecanismos de gestão, sendo potencialmente capazes de produzir impactos sobre os sistemas e instituições escolares, alterando o seu funcionamento e 0 modo como vêm organizando o seu trabalho (Adrião, 2001).

O Estado passa a adotar, na gestão da educação pública, como diz Afonso (1998), um ethos competitivo decalcado no que tem se designado por neodarwinismo social, passando a admitir a lógica do mercado com a importação para o domínio público de modelos de gestão privada, cuja ênfase é posta nos resultados ou produtos dos sis- 
temas educativos. Como assinala Walford (1990), esta ideologia da privatização, ao enaltecer o capitalismo de livre-mercado, conduziu a alterações e mudanças fundamentais no papel do Estado, tanto ao nível local, como ao nível nacional. Neste sentido, por exemplo,

diminuir as despesas públicas exigiu não só a adopção de uma cultura gestionária (ou gerencialista) no sector público, como também induziu a criação de mecanismos de controlo e responsabilização mais sofisticados. A avaliação aparece assim como um pré-requisito para que seja possível a implementação desses mecanismos. (Afonso, 1998, p.113)

O u seja, a noção de quase-mercados supõe regulamentação governamental, para o que os sistemas de avaliação, muitas vezes reduzidos a procedimentos de medida e de fiscalização, são muito funcionais.

Manifestação de Maria Helena G uimarães Castro (1998, p. 9), dirigente do INEP-MEC nas duas gestões do presidente Fernando Henrique Cardoso (1995-2002), é ilustrativa do lugar estratégico da avaliação na gestão educacional. Partindo da constatação da remodelação do papel do Estado, refere-se a medidas semelhantes que vêm sendo adotadas "em todos os países, como a privatização das empresas estatais, a desregulamentação da economia tendo por escopo estimular os investimentos privados, a realização de parcerias com o setor empresarial para ampliação da oferta de serviços públicos e o fortalecimento do papel regulador do Estado", e afirma que "sai de cena o Estado-executor, assumindo seu lugar o Estado-regulador e o Estado-avaliador".

Para evidenciar como se concretizou no Brasil essa concepção de gestão, passamos a apresentar as iniciativas de avaliação direcionadas à educação básica e superior implementadas nos últimos anos. São focos de nossas considerações o Sistema Nacional de Avaliação da Educação Básica (SAEB), o Exame Nacional do Ensino Médio (ENEm) e o Exame Nacional de Cursos (ENC), implementados pelo poder executivo federal, que se apresentam como avaliações de escolas, de egressos do ensino médio e de concluintes do ensino superior, respectivamente. ${ }^{4}$

\section{Avaliação da educação básica}

Nos anos finais da década de 1980 registra-se a primeira iniciativa de organização de uma sistemática de avaliação do ensino fundamental e médio, em âmbito nacional. Esta sistemática é denominada pelo MEC, a partir de 1991, de Sistema Nacional de Avaliação da Educação Básica (SAEB). ${ }^{5}$ O SAEB toma como um dos indicadores 
da avaliação o desempenho em provas de uma amostra de alunos do ensino fundamental e médio, de todas as Unidades Federadas.

Conforme Relatório Nacional do Sistema de Avaliação do Ensino Básico de 1990 (1991, p. 7), pretende-se, com o estudo de rendimento dos alunos, "detectar, primeiramente, os problemas de ensino-aprendizagem existentes e, em segundo lugar, determinar em que condições (de gestão, de competência docente, de alternativas curriculares etc.) são obtidos melhores resultados e que áreas exigem uma intervenção para melhorar as condições de ensino".

Para tanto, além de medir o desempenho escolar, o SAEB coleta informações sobre características dos alunos, professores e diretores, bem como das condições físicas e equipamentos das escolas.

D efine-se o SAEB Como um sistema de monitoramento contínuo, capaz de subsidiar as políticas educacionais, tendo como finalidade reverter 0 quadro de baixa qualidade e produtividade do ensino, caracterizado, essencialmente, pelos índices de repetência e evasão escolar.

$O$ delineamento assumido pelo SAEB encontra respaldo em argumentos que se alinham na direção de justificar a avaliação como instrumento de gestão educacional, tais como: possibilidade de compreender e intervir na realidade educacional, necessidade de controle de resultados pelo Estado, estabelecimento de parâmetros para comparação e classificação de desempenhos, estímulo por meio da premiação, possibilidade de controle público do desempenho do sistema escolar. ${ }^{6}$

Estes argumentos expressam, no limite, uma concepção acerca do papel do Estado na condução das políticas educacionais. Ao que parece, a questão central nesta proposta não é a de buscar subsídios para intervenções mais precisas e consistentes do poder público, ou seja, uma análise das informações coletadas para definição e implementação de políticas para a educação básica, mas sim difundir, nos sistemas escolares, uma dada concepção de avaliação, que tem como finalidade a instalação de mecanismos que estimulem a competição entre as escolas, responsabilizando-as, em última instância, pelo sucesso ou fracasso escolar.

Mesmo considerando que o SAEB, por seu desenho amostral, não permite comparação entre a totalidade das escolas de cada unidade federada, há que se observar que tem permitido a comparação e classificação das mesmas, estimulando a competição entre elas no sentido de galgarem melhores postos no ranking. A título de exemplo, 
lembramos de uma unidade federada que assumiu como alvo a ser atingido "entrar no G 7", o que significava ser classificada, a partir dos resultados do SAEB, entre as sete "melhores" do país.

Ao comentar sobre eventuais impactos do SAEB, Bonamino (2002, p.181-182) considera que, em

sua forma atual, o SAEB não parece possuir o poder de influenciar o estilo cognitivo dos alunos e professores em cada disciplina escolar. O SAEB ainda não pode ser considerado como uma avaliação reguladora da aprendizagem, nem como uma avaliação formativa, baseada na constante explicitação dos elementos a considerar, das estratégias a adotar, dos problemas a resolver. (....) Para equacionar mais adequadamente 0 alcance e 0 impacto que 0 SAEB pode vir a ter so bre os aspectos mencionados, certamente será necessário acompanhar a forma como os estados estão entendendo e implementando a denominada cultura de avaliação. É sempre possível, e já há alguns sinais concretos a respeito, que ao reverberar nos estados e municípios o modelo sofra uma reconversão, passando a tornar-se censitário. Nesses casos, ele se tornaria mais propenso a aderir às teses sobre a regulação pedagógica e financeira da vida escolar que, até 0 momento, o desenho do SAEB parece não endossar.

Se aceita a suposição de que o SAEB, pelo seu delineamento, não tem potencial para produzir alterações nas práticas escolares, de ensino e de aprendizagem, no sentido de seu aprimoramento, cabe uma indagação: qual a sua intencionalidade? Sua finalidade parece ser o fortalecimento do papel regulador do Estado, por meio da responsabilização, no caso do SAEB, das unidades federadas pelos resultados escolares. Como disse Castro (1996, p. 14), em conferência intitulada "Projeto nacional: o papel da avaliação", "(...) a tendência vai no sentido de descentralizar o que for possível. A idéia geral é: o Governo Federal não tem que fazer, ele faz acontecer". E um meio de "fazer acontecer" é estimular a competição.

Se com 0 SAEB 0 que se provoca é a competição entre unidades federadas, no caso de sistemas criados pelas próprias unidades federadas, com desenho censitário, esta lógica competitiva é transferida para as escolas, acrescida do poder de conformar os currículos escolares. Nessa perspectiva, vale lembrar o significado que podem assumir os Parâmetros Curriculares Nacionais, no sentido de se constituírem nos padrões de desempenho esperados, ou seja, os conteúdos a serem ensinados nas escolas serão aqueles que serão "cobrados" nas provas, elaboradas pelas instâncias externas à escola (O liveira, 2000).

A fim de evidenciar a possibilidade de uso de resultados de sistemas de avaliação para premiação ou punição de escolas, o que certamente potencializa o poder dos testes de rendimento virem a conformar 0 
que se ensina nas escolas, reproduzimos uma notícia divulgada em janeiro de 2002, a respeito do estado de São Paulo, cujo sistema de avaliação, na ocasião, era censitário. 0 título é "G overno paulista premia escolas e alunos com maior desempenho", seguido do seguinte texto:

D as 345 escolas selecionadas de um total de 4.100 estabelecimentos, 25 receberam pacotes de viagens para a região amazônica. Os demais roteiros das viagens realizadas em dezembro último incluíram Brasilia e região do D istrito Federal, Salvador e Porto Seguro e cidades históricas de Minas G erais, Rio de Janeiro e Petrópolis [sic], Paraná e Santa Catarina. Mais 7 mil pessoas de 782 escolas estarão viajando até março próximo para municípios do interior paulista. Neste programa estão sendo investidos cerca de R \$ 4 milhões. (http:/ / ultimosegundo.ig.com.br)

Nessa mesma direção, durante o segundo governo Covas, a Secretaria Estadual de Educação de São Paulo atribuiu cores às escolas públicas, de acordo coma a classificação obtida nos processos de avaliação implementados.

Não se pretende, com as considerações aqui esboçadas, desprezar o valor da avaliação externa, onde se situa a apreciação do trabalho escolar pelas instâncias administrativas do sistema, a qual, no entanto, não deve se traduzir na aplicação de testes de rendimento escolar. Potencializar a dimensão educativa/ formativa da avaliação certamente supõe a promoção da autonomia pedagógica e didática da escola e não a sua conformação, que se realiza quando se delimita que conhecimento deverá ser legitimado pela escola, cujo cumprimento é condição para sua premiação.

\section{Exame do ensino médio}

O Exame Nacional do Ensino Médio tem uma especificidade a ser observada: apresenta-se como um exame em que o aluno é que decide sobre a conveniência de participar, após a conclusão do ensino médio, sob a promessa de que "seu futuro passa por aqui", frase constante de material informativo divulgado pelo INEP.

De modo explícito, fica evidenciada a visão individualizada com que é tratado o processo educacional, sendo atribuída, ao aluno, individualmente, a responsabilidade pelas eventuais competências ou incompetências que o exame vier a demonstrar. No documento do INEP, já mencionado, lê-se: "O ENEM poderá lhe mostrar, enfim, em que áreas você precisa caprichar ainda mais para ter sucesso pessoal e 
profissional. D esse modo, você terá uma avaliação do seu potencial e poderá tomar as decisões mais adequadas aos seus desejos e às suas escolhas futuras". Em nenhum momento se lê algo como: 0 ENEM poderá mostrar, enfim, quais vêm sendo os resultados das ações empreendidas pelos órgãos governamentais. Ou algo do tipo: MEC: seu futuro passa por aqui!

Além de atribuir ao potencial do aluno o seu sucesso pessoal e profissional, abstraindo os fatores econômicos e sociais que condicionam tal ou qual trajetória escolar e social, cabe ainda observarmos que, tal como se apresenta, o ENEM tende, no limite, a penalizar os alunos oriundos de escolas que contam com precárias condições de funcionamento, oferecidas pelo poder público, que, tradicionalmente, atendem a população pobre.

Trata-se, portanto, de uma medida de resultado final, interpretada em uma perspectiva individualizada, desconsiderando as condições do sistema de ensino que, sem dúvida, induzem a produção de "competências" ou "incompetências" nos alunos.

Cabe ainda indagarmos, que benefícios poderá trazer aos alunos? 0 que poderá ser feito retroativamente? Diante da constatação de dadas incompetências, o que poderá um aluno egresso da escola pública fazer? Exigir do poder público um processo de ensino que garanta seu direito à real escolarização? Nada nesta direção é expresso nos seus objetivos, elencados no "D ocumento Básico", elaborado pelo INEP/ MEC.

Ao que parece, pelos objetivos anunciados, o ENEM pretende se legitimar como mecanismo de referência a processos seletivos, seja para cursos profissionalizantes, para cursos superiores ou mesmo para inserção no mercado de trabalho.

Será que é nesta direção que devem ser conduzidos os esforços e recursos de um Ministério da Educação? Em um país com altos índices de exclusão educacional e social, que sentido têm iniciativas voltadas para classificação de alunos, de acordo com competências individuais, medidas por meio de testes?

Buscar responder a essas questões, que possibilitam dar transparência às políticas em curso, deve ser um passo que antecede a decisão de "adotar os resultados do ENEM", seja qual for o processo seletivo em pauta, pois sua adoção significa, no limite, a legitimação não apenas do ENEM, mas das diretrizes e propósitos da política vigente. 
Comparando-se com o SAEB, é possível afirmar que o ENEM apresenta-se com um potencial maior de condicionar os currículos escolares, ou seja, ensina-se para a obtenção de bons resultados no Exame. Aliás, já há até "cursinhos" preparatórios para 0 ENEM!

\section{O Exame Nacional de Cursos}

Com relação à avaliação do ensino superior, particularmente sobre a graduação, contamos com estudos que vêm registrando e analisando sua evolução no Brasil, trazendo importantes informações e reflexões, que possibilitam uma compreensão dos programas governamentais implementados nos anos recentes. Tais estudos têm tido como espaço privilegiado para sua divulgação a Revista da Rede de A valiação Institucional da E ducacão Superior, ${ }^{7}$ alguns dos quais tomamos como referência para sumariar as propostas e práticas em curso.

Como principal procedimento avaliativo, o MEC instituiu, a partir de 1995, os exames nacionais (Lei $9.131,^{8}$ de $24 / 11 / 95$ ), que, segundo os termos de seu artigo 3o, são destinados a "aferir os conhecimentos e competências adquiridos pelos alunos em fase de conclusão dos cursos de graduação". Este foi o único procedimento de avaliação citado no texto da referida Lei, embora faça referência a que 0 MEC fará uso "de procedimentos e critérios abrangentes dos diversos fatores que determinam a qualidade e a eficiência das atividades de ensino, pesquisa e extensão."

O u seja, de uma perspectiva de avaliação institucional, abrangente e processual, que vinha sendo construída por meio do Programa de Avaliação Institucional das Universidades Brasileiras (PAIUB), desde 1994, dá-se ênfase aos resultados obtidos individualmente pelos alunos, em provas realizadas ao final de um dado curso. Embora não formalmente, tal encaminhamento foi expressão da "desativação" do PAIUB. 0 destaque dado para a avaliação de produto não promove a consolidação de uma cultura de avaliação no interior das instituições, que vinha sendo estimulada pelo PAIUB, mas, ao contrário, tende a reduzir a atividade avaliativa ao procedimento de medida ou quantificação de resultados, sendo monopólio do governo federal a determinação de que produtos são considerados válidos, ou seja, no limite estamos assistindo ao uso da avaliação como dispositivo de regulação educacional e social (MEC/ SESU, Programa de Avaliação Institucional das Universidades Brasileiras, 1994). 
O "provão", como vem sendo chamado o Exame Nacional de Cursos, provocou críticas de alunos e de instituições universitárias. A apreciação de Belloni (1996, p. 11) transcrita a seguir ilustra o conteúdo principal das críticas proferidas:

Trata-se de uma simples medição de resultado final, um procedimento tradicional e insuficiente de avaliação, pois não considera fatores do processo de aprendizagem e das condições institucionais. Não oferece elementos paraa melhoria da instituição e do sistema, pois não identifica as causas das dificuldades; não beneficia o estudante, pois nada poderá ser feito retroativamente. Não corresponde, portanto, ao objetivo fundamental da avaliação qual seja o de melhoria e aperfeiçoamento das instituições ou do sistema. Além disso, pode vir a estimular o aparecimento de um comércio de cursinhos preparatórios, pois o desempenho da prova poderá se transformar em critério de diferenciação entre portadores de um mesmo diploma.

Se as críticas feitas nessa direção não tiveram força para suspender tal procedimento de medida, possivelmente, provocaram a promulgação, pelo MEC, do Decreto no 2.026, de 14/10/96, antes mesmo que se realizasse o primeiro Exame, em novembro de $1996 .{ }^{9} \mathrm{O}$ referido D ecreto prevê que a avaliação de cursos e de instituições de ensino superior contemple as seguintes dimensões:

- análise dos principais indicadores de desempenho global do sistema nacional de ensino superior, por região e unidade da federação, segundo as áreas do conhecimento e o tipo ou a natureza das instituições de ensino;

- avaliação do desempenho individual das instituições de ensino, compreendendo todas as modalidades de ensino, pesquisa e extensão;

- avaliação do ensino de graduação, por curso, por meio da análise das condições de oferta pelas diferentes instituições de ensino e pela análise dos resultados do Exame Nacional de Cursos;

- avaliação dos programas de mestrado e doutorado, por área do conhecimento.

A noção de medida de resultado é ampliada para uma perspectiva de avaliação, sendo previstos, além dos Exames, a avaliação das instituições e de cursos por comissões externas e a auto-avaliação da instituição. Ou seja, a avaliação do ensino superior resultará da agregação de resultados produzidos por diferentes instâncias: pela CAPES (pós-graduação stricto sensu); pela Secretaria de Avaliação e Informa- 
ção Educacional do MEC - SEDIAE (Exame Nacional e análise de indicadores de desempenho global); por especialistas (graduação) e instituições de ensino (auto-avaliação). Como observa Luiz Antônio $\mathrm{Cu}$ nha (1997, p. 41) "a avaliação do ensino superior no Brasil foi concebida para se desenvolver de modo fragmentado, dificilmente consolidável e compatilizável pela SESU", ou mesmo pelo Conselho Nacional de Educação, ao qual caberá emitir parecer sobre os resultados da avaliação.

Mesmo se considerarmos que, apesar da fragmentação, há uma intencionalidade de proceder a uma avaliação mais abrangente das instituições, ficam indagações quanto ao uso de seus resultados, especialmente quando se observa a visibilidade que têm tido na mídia as pontuações decorrentes do "provão" e o seu uso como referência de qualidade de um dado curso e, por decorrência, da instituição.

Afora 0 incentivo à competitividade, provocado pelo estabelecimento de ranking de instituições, que expressa a transposição da lógica de mercado para a gestão do sistema educacional, cabe indagarmos sobre possíveis usos dos resultados, seja no estabelecimento de critérios para alocação de recursos financeiros entre as instituições, tendo em conta seu bom ou mau desempenho, seja na política de financiamento do ensino superior - temos assistido investidas na direção de questionar a validade de manutenção de universidades públicas gratuitas, a partir de apreciações acerca de seu custo e produtividade.

Q uanto ao seu impacto em instituições/ cursos avaliados, já é possível identificar iniciativas que vêm sendo tomadas em decorrência do conceito obtido. Tomando como referência duas pesquisas realizadas sobre o "provão" (Santoro, 1999, e Santos, 2001), manifestações que vêm sendo divulgadas, sistematicamente, na imprensa, bem como depoimentos informais de profissionais vinculados a Instituições de Ensino Superior, é possível constatar sua influência.

A primeira delas é a aprovação de sua realização, reconhecendo que seus resultados espelham aprendizagem dos alunos, e esta reflete a qualidade da instituição. Santos (2001, p. 140), ao analisar o que significa esta aprovação do Exame, indica que ela legitima:

a) a idéia da possibilidade de todos os alunos aprenderem da mesma forma uma lição, por estarem sujeitos à mesma percepção-impressiva;

b) a idéia de que essa aprendizagem, reificada, pode ser objetivamente medida através de uma prova; 
c) que a média das notas numéricas decorrentes das provas dos alunos de uma instituição mede também o ensino, já que estão numa relação de causa-efeito;

d) essa mesma média indica a qualidade de uma instituição e, portanto, é procedimento correto classificá-la em ordem decrescente segundo essas médias.

Evidencia-se também um reconhecimento de que 0 ENC tem provocado uma reação das instituições, especialmente as privadas, a partir dos resultados por elas obtidos. Embora não se possa generalizar, reproduzimos o que comenta Santos (op. cit.) na conclusão de seu estudo, pois sua constatação caminha na mesma direção da maior parte das manifestações, a que temos tido acesso, de professores atuantes em Instituições de Ensino Superior:

O ENC realmente provocou agitação nos meios acadêmicos, mas se observarmos as respostas dos professores, vemos que as ações ensejadas o foram, não no sentido da melhoria do curso, mas no sentido de 'preparar o graduando para o provão'. Mudanças foram realizadas, medidas emergenciais foram tomadas, não para atualizar currículos, programas, bibliografia, inovar nos métodos didáticos, mas apenas para preparar melhor o aluno para o provão. Isso, certamente, não é melhorar a qualidade dos cursos. 0 fim das ações foi melhorar a nota da instituição no provão, com vistas a uma melhor classificação numa lista pública que pode levar à execração. (Santos, 2001, p. 141142)

Comenta ainda que com base nas provas já realizadas, "os professores estão fazendo ajustamentos em seus programas de trabalho e isso, fatalmente, conduzirá à fixação de um 'conhecimento oficial' (...) em âmbito nacional" (idem, ibid.).

Mesmo um dos defensores públicos do provão, Cláudio Moura Castro (2002, p. 20), reconhece que este tem "efeitos colaterais", afirmando:

Um deles é enrijecer os currículos, tirando dos cursos a liberdade de experimentar. O utro é a questão do valor adicionado. Sabemos que $80 \%$ dos resultados são determinados por diferenças dos alunos, já no vestibular. Portanto, não podemos execrar um curso que ofereça um ensino correto cujo único pecado é ter alunos mais fracos.

Veja-se a gravidade dos "efeitos" mencionados, que entendemos não são colaterais, mas sim intrínsecos ao "provão": uniformizar currículos e intensificar desigualdades, penalizando os já penalizados! 
Além disso, a crença no poder indutor da competição, gerada pela divulgação dos rankings, desconsidera os seus limites. Exatamente por tratar-se de um mercado segmentado, nem todos buscarão situarse nos primeiros lugares do ranking, mas sim no melhor lugar possível em função dos valores investidos. Nesse tipo de lógica, há espaço, também, para a instituição de baixa qualidade a baixo custo.

Sabemos que a avaliação não é um processo meramente técnico, portanto a análise dos pressupostos que a informam e de suas conseqüências sociopolíticas é necessária. Neste sentido,

tal como vem se buscando a transparência dos resultados do trabalho universitário, há que se exigir igual tratamento aos órgãos governamentais que, de fato, detêm, atualmente, o poder de mando da educação (...) seria a avaliação das reais perspectivas governamentais, da visão que esses organismos detêm sobre a Universidade. (Amorim \& Sousa, 1994, p. 127)

Em relação ao ensino superior, cabe um alerta: talvez, em breve, não mais estejamos clamando pela autonomia das instituições, mas sim pelo direito dos Estados nacionais definirem suas políticas educacionais, considerando a decisão da Organização Mundial do Comércio de tratar 0 ensino superior como um dos setores de serviço incluído no Acordo G eral sobre o Comércio de Serviços (GATT em inglês), retirando, na prática, a autoridade e autonomia das nações na implementação de suas políticas para este nível de ensino. Ainda é oportuno registrar o potencial excludente contido no tratamento do ensino superior como mercadoria a ser livremente comercializada. Como diz Marco Antonio Dias (2002, p. 2), "o desenvolvimento da sociedade do conhecimento que representaria, se bem administrado, um grande instrumento para dividir as riquezas no mundo, corre o risco de se tornar um fator adicional de dominação por parte de poucos e de exclusão da maioria".

\section{Avaliação: tendências e tensões}

De modo dominante, a lógica intrínseca às propostas avaliativas que vêm se realizando no país, particularmente a partir da década de 1990 e direcionadas aos diversos níveis de ensino, é a de atribuição de mérito com fins classificatórios. O que define de modo mais explícito as finalidades a que vem servindo a avaliação, para além dos delineamentos adotados, é o uso que se faz de seus resultados, qual seja, a produção de classificações que apóiam a hierarquização de unidades federadas, de instituições ou de alunos. 
A crença é a de que as pressões geradas pela competição, suscitada pelos procedimentos avaliativos, farão com que sejam mobilizados processos e recursos que resultarão em melhoria da qualidade de ensino. D esse modo, pressupõe-se a aceitação da desigualdade como condição mesma de produção de qualidade, pois sendo diferentes e diversificadas as condições dos sistemas e unidades escolares estaríamos caminhando na direção de intensificar os processos de segregação e seleção educacional e social.

Nessa medida, até mesmo a pluralidade de procedimentos avaliativos implementados (SAEB, ENEM, ENC e outros) configura-se como meros instrumentos que podem ser alterados e/ ou até mesmo abandonados em prol do objetivo maior de disseminar uma cultura avaliativa de natureza competitiva e estratificadora.

0 recurso ao conceito de quase-mercado para interpretar as modificações em curso na educação pública permite-nos compreender a aplicação, na gestão dos sistemas educacionais, dos princípios e valores da iniciativa privada, que trazem consigo um projeto de sociedade que certamente não contém a utopia da transformação. Sem dúvida, a avaliação é um processo capaz de direcionar projetos e ações e o que se evidencia com as práticas em curso é a perspectiva da reprodução e intensificação das desigualdades educacionais e sociais.

Tais valores não são estranhos à sociedade capitalista, tendo portando condições de hegemonizar discursos e práticas. Entretanto, para a tradição educacional brasileira, que cultua liberais como Anísio Teixeira e os Pioneiros de 1932, a difusão de tal versão do liberalismo com uma intensidade inédita não deixa de ser chocante.

Recebido e aprovado em agosto de 2003.

\section{Notas}

1. Percebe-se essa lógica no caso das estradas. A privatização de uma estrada não produz o efeito indutor desejado, pois não há, ao lado, outra estrada que possa "competir" com a primeira, estando, então, limitada à capacidade de se aperfeiçoarem pela concorrência.

2. Vale lembrar que os EuA não têm um ministro da Educação, mas um secretário, pois as responsabilidades pelo atendimento ao Direito à Educação cabem aos estados. 0 governo federal atua no sentido de financiar programas especiais e realizar a avaliação do sistema.

3. As iniciativas de avaliação aqui tratadas foram desencadeadas pelo Ministério da Educação (MEC) nas gestões do presidente Fernando Henrique Cardoso. No atual governo, de Luis Inácio Lula da Silva, não se tem registro de alterações ocorridas nos procedimentos aqui 
relatados, excetuando-se a criação do exame de Certificação de Professores, Portaria 1403/ 2003, que sugere uma continuidade da lógica que vem presidindo as políticas de avaliação. O utra iniciativa que merece registro foi a constituição de uma Comissão, presidida pelo Prof. José Dias Sobrinho, incumbida de apresentar uma nova proposta de avaliação para 0 ensino superior. Até a finalização deste texto, seus resultados ainda não eram conhecidos. Também não é possível inferir o eventual compromisso dos atuais gestores do MEC com a implantação das sugestões que serão apresentadas por esta Comissão.

4. Parte das considerações aqui constantes sobre as iniciativas de avaliação integram publicação anterior de Sousa (2001).

5. Caracterização mais detalhada das alterações ocorridas no SAEB, desde a primeira iniciativa em 1988, é apresentada por Bonamino (2002).

6. A título de ilustração de como são apresentados tais argumentos, ver Waiselfisz, 1993; Castro, 1994; Instituto Herbert Levy, 1993; Fletcher, 1994.

7. A Revista é uma publicação da Rede de Avaliação Institucional da Educação Superior (RAIEs).

8. Lei $n^{0}$ 9.131/ 95, que altera dispositivos da Lei $n=4.024 / 61$, trata da criação do Conselho Nacional de Educação e institui os "Exames Nacionais".

9. Em 1996 foram examinados os alunos concluintes dos cursos de Direito, Administração e Engenharia Civil; em 1997 foram também examinados os concluintes dos cursos de Engenharia Química, Veterinária e O dontologia. A cada ano, novos cursos vêm sendo incorporados.

\section{Referências bibliográficas}

ABRUCIO, F.L. Os avanços e os dilemas do modelo pós-burocrático: a reforma da administração pública à luz da experiência internacional recente. In: Bresser Pereira, L.C.; Spink, P. (O rg.). R eforma do E stado e administração pública gerencial. São Paulo: FGV, 1999.

ADRIÃO, T.M.F. A utonomia monitorada como eix o de mudança: padrões de gestão no ensino público paulista (1995-1998). 2001. Tese (D outorado) - Faculdade de Educação da usp, São Paulo.

AFO NSO, A.J. Políticas educativas e avaliação educacional: para uma análise sociológica da reforma educativa em Portugal (1985-1995). Portugal: IEP/ CEEP/ Universidade do Minho, 1998.

AMO RIM, A.; SO USA, S.M.Z.L. Avaliação institucional da universidade brasileira: questões polarizadoras. E studos em A valiação E ducacional, São Paulo, n. 10, p. 123-136, jul./ dez. 1994.

AZEVED O, M.L.N. N eoliberalismo e educação: novo conflito entre o público e o privado. 1995. Dissertação (Mestrado) - Universidade Federal de São Carlos, São Carlos. 
BELLONI, I. A universidade e o compromisso da avaliação institucional na reconstrução do espaço social. A valiação, Campinas, v. 1, n. 2, p. 514, 1996.

BERLINER, D.; BIDDLE, B. The manufactured crisis: myths, fraud and the attack on America's public schools. Reading, Mass.: AddisonWesley, 1995.

BIERLEIN, L. Controversial issues in educational policy. Newbury Park, Cal.: Sage, 1993.

BO NAMINO, A.C. Tempos de avaliação educacional: o SAEB, seus agentes, referências e tendências. Rio de Janeiro: Q uartet, 2002.

BRASIL. Lei n. 9.131, de 24 de novembro de 1995. Altera dispositivos da Lei ํㅡ 4.024, de 20 de dezembro de 1961, e dá outras providências. D iário 0 ficial da U nião. Brasília, DF, 25 nov. 1995.

BRASIL. Lei n. 9.394 de 20 de dezembro de 1996.Estabelece as Diretrizes e Bases da Educação Nacional. D iário 0 ficial da U nião. Brasília, DF, 23 dez. 1996.

BRA SIL. Ministério de Educação. Relatório $\mathrm{N}$ acional do Sistema de A valiação do E nsino Básico de 1990. Brasília, DF, 1991.

BRASIL. Ministério de Educação. Secretaria de Educação Superior. Programa de A valiação Institucional das U niversidades Brasileiras: PAIUB. Brasília, DF.: MEC/ SESU, 1994.

BRA SIL. Ministério da Educação e do D esporto. Instituto Nacional de Estudos e Pesquisas Educacionais. ene : seu futuro passa por aqui. Brasília, DF.: MEC/ INEP, 1999.

BRASIL. Ministério da Educação e do Desporto. Instituto Nacional de Estudos e Pesquisas Educacionais. e n E M documento básico. Brasília, DF.: MEC/ INEP, 1999.

BRESSER PEREIRA, L.C. Reforma do E stado para a cidadania: a reforma gerencial brasileira na perspectiva internacional. São Paulo: Editora 34; Brasília: ENAP,1988.

BURTLESS, G. D oes money matter?: the effect of school resources on student achievement and adult success. Washington, DC: Brookings, 1996.

CASTRO, C.M. E ducação brasileira: consertos e remendos. Rio de Janeiro: Rocc0, 1994. 
CASTRO, C.M. Q uem tem medo da avaliação? V eja, São Paulo, 10 jul. 2002, p. 20.

CASTRO, M.H.G. In: SEMINÁRIO INTERNACIONAL DE AVALIAÇÃO DA EDUCAÇÃO, 1995, Rio de Janeiro. A nais... Rio de Janeiro: Fundação Cesgranrio, 1996. p. 11-16.

CASTRO, M.H.G. Palestra inaugural. In: SEMINÁRIO INTERNACIONAL DE AVALIAÇÃO EDUCACIO NAL, 1997, Rio de Janeiro. A nais... Brasília, DF: INEP, 1998. p. 9-11.

CHUBB, J.; MOE, T. Politics, mark ets \& A merica's schools. Washington, DC: Brookings, 1990.

CO OKSON, P. School choice: the struggle for the soul of American education. New Haven: Yale University, 1994.

CUNHA, L.A. Nova reforma do ensino superior: a lógica reconstruída. C adernos de Pesquisa, São Paulo, n. 101, p. 20-40, jul. 1997.

CURY, C.R.J. Reforma universitária na nova Lei de Diretrizes e Bases da Educação Nacional? Cadernos de Pesquisa, São Paulo, n. 101, p. 319, jul. 1997.

DELORS, J. E ducação: um tesouro a descobrir; relatório para a UNESCO da Comissão Internacional sobre Educação para o século XXI. 3. ed. São Paulo: Cortez; MEC, 1999.

DIAS, M.A.R. E ducação superior: bem público ou serviço comercial regulamentado pela oмc? maio 2002. (versão preliminar) Mimeografado.

DIAS, R. 0 público e 0 privado na educacãa: a experiência da privatização do ensino em Maringá e temas afins. Maringá: Secretaria da Educação do Município de Maringá, 1995.

FLETCHER, P.R. A teoria de resposta ao item: medidas invariantes do desempenho escolar. Ensaio, Rio de Janeiro, v. 1, n. 2, p. 21-28, 1994. FRIED MAN, M. Capitalismo e liberdade. São Paulo: Nova Cultural, 1985 GATTI, B.A. Testes e avaliações do ensino no Brasil. E ducação \& Seleção, São Paulo, n. 16, p. 33-42, 1987.

GENTILI, P. Adeus à escola pública. In: GentiLI, P. (Org.). Pedagogia da ex clusão: 0 neoliberalismo e a crise da escola pública. Petrópolis: Vozes, 1995. 
GENTILI, P.; SILVA, T.T. N eoliberalismo, qualidade total e educação: visões críticas. 2. ed. Petrópolis: Vozes, 1995.

GOLDBERG, M.; RENTON, A.M. A nation at risk: ugly duckling no longer. In: G insberg, R.; Plank, D. Comissions, reports, reforms and educational policy. Westport, Conn.: Praeger, 1995.

HANUSHEK, E. Making schools work: improving performance and controlling costs. Washington, D C: Brookings, 1994.

INSTITUTO HERBERT LEWY. E nsino fundamental e competitividade empresarial: uma proposta para a ação do governo. São Paulo, 1992.

LOJKINE, J. A revolução informacional. Trad. José Paulo Netto. São Paulo: Cortez, 1995.

LUND, L.; WILD, C. Ten years after A N ation at Risk. New York: The Conference Board, 1993. (Report n. 1041).

OLIVEIRA, R.P. Reformas educativas no Brasil na década de 90. In: Catani, A.M.; O liveira, R.P. Reformas educacionais em Portugal e no Brasil. Belo Horizonte: Autêntica, 2000. cap. 4, p. 77-94.

ORFIELD, G.; KORNHABER, M. Raising standards or raising barriers?: inequality and high-stake testing in public education. New York: The Century Foundation, 2001.

PESTANA, M.I. O sistema de avaliação brasileiro. In: SEMINARIO INTERNACIONAL DE AVALIAÇÃO EDUCACIONAL, 1998, Brasília. A nais... Brasília, DF: INEP, 1998. p. 15-30.

PETERSEN, P. (Ed.). 0 ur schools and our future: are we still at risk? Washington, DC: Hoover, 2003.

PILATI, O. Sistema Nacional de Avaliação da Educação Básica. E nsaio, Rio de Janeiro, v. 2, n. 1, p. 11-30, 1994.

SALM, C. E scola e trabalho. São Paulo: Brasiliense, 1980.

SANTORO, E.D. E xame nacional de cursos (provão) na ótica dos alunos de D ireito de uma universidade particular. 1999. Dissertação (Mestrado) - Universidade Mackenzie, São Paulo.

SANTOS, W. 0 provão: para além do discurso oficial, representação do professor e anatomia do modelo. 2001. 2v. Tese (D outorado) Pontifícia Universidade Católica de São Paulo, São Paulo. 
SO USA, S.M.Z.L. Avaliação do rendimento escolar como instrumento de gestão educacional. In: O liveirA, D .A. (O rg.). G estão democrática da educação. Petrópolis: Vozes, 1997.

SO USA, S.M.Z.L. Parceria escola-empresa no Estado de São Paulo: mapeamento e caracterização. E ducação \& Sociedade, Campinas, v. 21, n. 70, p. 171-188, abr. 2000.

SO USA, S.M.Z.L. Avaliação e políticas educacionais: iniciativas em curso no Brasil. In: Hidalgo, A.M.; Silva, I.L.F. (O rg.). E ducação e E stado: as mudanças nos sistemas de ensino do Brasil e do Paraná na década de 90. Londrina: UEL, 2001. p. 69-100.

SO USA, S.M.Z.L. Possíveis impactos da avaliação externa no currículo escolar. In: RosA, D.G.; So uZA, V.C. (O rg.). Políticas organizativas e curriculares, educação inclusiva e formação de professores. Rio de Janeiro: D P\&A, 2002. p. 23-38.

THE NATIONAL COMISSION ON EXCELLENCE IN EDUCATION. A nation at risk: the imperative for educational reform. Washington, DC: U.S. G overnment Printing Office, 1983.

VIANNA, H.M. Acesso à universidade: um estudo de validade. E ducação \& Seleção, São Paulo, n. 15, p. 83-146, 1987.

WAISELFISZ, J. Sistema de avaliação do desempenho escolar e políticas públicas. E nsaio, Rio de Janeiro, v. 1, n. 1, p. 5-22, 1993.

WHITTY, G. Controle do currículo e quase-mercados: a recente reforma educacional na Inglaterra e no País de Gales. In: WARDE, M.J. (O rg.). N ovas políticas educacionais: críticas e perspectivas. São Paulo: PUC, 1998. p. 193-213. 